\title{
Deepening Our Students' Appreciation of Others: Using Multicultural Field Experience in an Online Education Course
}

\author{
Rebecca A. Wentworth \\ Sam Houston State University
}

\author{
Lisa O. Brown \\ Sam Houston State University
}

\begin{abstract}
This qualitative research project investigated the self-reported outcomes of an academic community engagement project completed by graduate teacher education students who tutored EC-12 children enrolled in Texas public schools. A document discourse analysis was conducted, and validity is preserved through use of contextualized quotes from student papers. The authors discuss their findings of student language related to describing their tutees and their experiences as well as reflections on professional growth. Unintended outcomes such as expressing elitism and over-correcting bias are also discussed. The authors conclude that despite unintended consequences, this and similar academic community engagement projects have a positive impact on teacher education students' dispositions toward diverse students and with careful, planned implementation can benefit the servant and the served.
\end{abstract}

\section{Introduction}

Grounding teacher education in real classroomsamong real teachers and students and among actual examples of students' and teachers' work-is an important, and perhaps even an essential, part of training teachers for the complexities of teaching in today's classrooms. Linda Darling-Hammond

Online education has changed a great deal since its earliest days when many purists were skeptical about the quality of education offered and the subsequent quality of graduates from online colleges. As computer platforms and applications have advanced, so has the quality of online coursework offered, which has in turn raised the general opinion toward digital degrees. In the discipline of teacher education, however, face-toface degrees are still viewed as preparing better teachers for certification and employability in the high school classroom by hiring principals [1].

After graduation and finding a teaching position, education professionals face another set of required tasks. For teachers, keeping current with professional advances and innovations is not an optional pursuit. Most states require that teachers obtain a minimum number of professional development (PD) hours each year they are certified to maintain their credentials. One way of fulfilling these requirements is by participating in $\mathrm{PD}$ opportunities offered by school districts and professional organizations. Such sessions are usually short term (one or two days) and address a specific teaching, technological, or management strategy. Critics of this type of PD cite the lack of depth of learning and experience offered. Indeed, most early childhood through $12^{\text {th }}$ grade (EC-12) educators are familiar with the term 'the inoculation method' of $\mathrm{PD}$, giving teachers a shot of training and hoping that it prevents or cures illness in the classroom.

Another way of fulfilling ongoing improvement required by state departments of education is as part of a planned degree program culminating in an advanced degree. Master's and doctorate degrees are offered in a variety of concentrations within the discipline of education, including educational technology, library sciences, curriculum, leadership, counseling, reading, and special education. Additionally, most districts offer financial incentives for completing advanced degrees, thereby enhancing the appeal of these degree programs for professional teachers.

For colleges that offer advanced teaching and education degrees, the task is to offer high-quality advanced degrees for busy professionals that honor not only the noble profession in which they work, but also their time commitments to job, extracurricular involvement, family, and self. With online education evolving into a highly competitive and academically viable option for today's postbaccalaureate learners, distance education is making high-quality degrees from reputable institutions available to learners who would have previously been geographically limited to only local programs. At the same time, schools and colleges of education must avoid becoming 'degree mills', awarding credits and degrees that reflect limited growth and 
little value added to the recipient as well as the community they serve.

The current manuscript describes the results of an in-depth look into the outcomes of an assignment intended to increase the impact of a multicultural academic community engagement (ACE) experience in a graduate education course. Students reflected on their experience completing nine hours of required face-to-face tutorials with a student who differed from them on a dimension of diversity. The researchers, using narrative analysis, looked at the language used by graduate education students in required written reflections to determine the impact of the project and whether or not modifications to the project were indicated.

\section{Literature Review}

\subsection{Online Education}

The numbers associated with online highereducation courses is staggering. At least 6.7 million students enrolled in online courses in 2012, with nearly $1 / 3$ of all active college students enrolling in at least one online course. Brown states, "There is a need for lifelong learning and distance learning provides that opportunity for many who may not have had access to learning prior to this technology" [2]. The growth rate of online-student enrollment is over nine percent and more than $69 \%$ of academic leaders surveyed stated that online learning is critical to long-term strategic planning. [3]. With demand of online courses increasing, colleges and universities must adapt to meet the demand. Increasing online course and degree offerings, however, should not be done at the expense of high quality educational experiences for students that produce high quality graduates for employment in business and industry. Nowhere is this balance more critical than in education programs, where graduates are headed into our EC-12 classrooms to educate and influence our children.

In a culture where nearly a quarter of academic leaders believe online education is inferior to faceto-face education [3] and where EC-12 hiring personnel give more consideration to graduates of face-to-face programs than to graduates of online programs [1], programs that offer online options for teachers and teacher candidates must be diligent in creating educational experiences that are rich and meaningful in order to close the perceived quality gap between their programs and traditional programs. One way of mitigating this gap and offering real-world experiences to students is by implementing an academic community engagement (ACE) component.

\subsection{Academic Community Engagement}

In this context, ACEing a course means to include an academic community engagement component to the course as a requirement of all students. ACEing is related to community service and volunteerism, but goes one step further than both of these by incorporating skills learned in the classroom with activities that benefit community groups. At our university, an ACE course earns special designation in the course offering guide and requires the following: (a) one or more course objectives must be addressed through the ACE activity; (b) a statement of the importance of ACE to the course must be included in the course syllabus; (c) a reflection assignment, which is included in the final course evaluation and grade, must be completed by all students; and (d) students must engage in at least three hours of ACE activities for every one hour of course credit.

Even with the above minimum standards in place, our university boasts over 200 ACEd courses with over 125 faculty members actively involved in ACE efforts. This may be due in part to the university's motto: The Measure of a Life is its Service. University leadership, faculty, students and alumni all embrace this motto, and during the 2011 2012 school year the College of Education estimates a $\$ 4.7$ million impact in the schools and community partners we serve. As part of the ACE initiative, ACEd courses across the entire university contributed 74,380 hours to our community in the Fall 2014 and Spring 2015 semester combined.

Service of this type is not only of benefit to the people we serve. The students also benefit from the community work in which they engage. Research shows that students who engage in ACE courses outperform their non-serving peers academically, develop stronger positive beliefs regarding serving their community, are more satisfied with their educational experience, and are more likely to stay in and complete their educational plan [4]. Additionally, "Community Engagement provides students with opportunities to synthesize, integrate and apply their knowledge. Such experience makes learning more meaningful and ultimately more useful because what students know becomes part of who they are" [5].

Anecdotally, the students also recognize the value of community engagement. On a course evaluation, one sociology student wrote, "Since working with Habitat for Humanity I better understand how collective behavior works. The readings have been helpful but working with Habitat has shown me that when people in the community join together with a positive purpose, it can be a social movement that attracts people from all walks of life." Additionally, Kuh states that experiencedbased education is a high-impact practice in colleges 
and universities, increasing student engagement in academics as well as in their community [6].

\subsection{Exposure to and Engagement with Diverse Students}

In teacher education programs, community engagement is even more important for developing our students into the educators and school leaders we want them to become; and in a society that is becoming increasingly diverse, educational professionals need to engage with members of diverse populations as a component of their formal education. Projections from the US Census predict children under 18 years old who belong to racial and ethnic minorities will reach $64 \%$ of the age group by 2060 [7]. Likewise, there is an ever-increasing demand to prepare teachers who can address the needs of ethnically and racially diverse learners. Banks argues that in order for the United States to support a civic democracy, the education system should promote a "cultural democracy" which empowers the learner's background, life experiences, and ethnic values [8].

In the state of Texas, as mandated by the Texas Education Association (which governs teacher certification), teacher preparation programs must include an experience working with diverse learners. Similarly, the newly-created Council for the Accreditation of Educator Preparation, a national accreditation association, includes exposure to and work with diverse students as a theme woven throughout their program standards, indicating that serving the needs of diverse learners is not only one component of an effective teacher-education program but it is a characteristic integrated into all components of effective teacher-education programs. This is echoed by research that indicates teaching candidates who engage in meaningful, professionally related activities are less likely to engage in cultural stereotyping and have improved cultural and racial understanding [9].

Educational research has indicated teachers often teach the "way they learn". However, research also indicates each person learns in a very individual way that may be different from how a teacher personally learns [10]. Additionally, many classroom teachers struggle to address the diverse needs of students. Kim and Yazdian believe "it is extremely difficult for teachers to possess such knowledge for a student group with whom they have never worked" [11].

Thus, to become more effective at teaching, great teachers use curriculum, teaching strategies, and assessments that meet all students' diverse learning needs. Numerous educators have advocated for culturally responsive teaching as a proactive pedagogy to meet the needs of diverse classes, engage diverse learning environments, and reflect on these students' diverse needs. Some researchers argue that teacher candidates "should have the opportunity to actively engage with diverse students through clinical placements, professional development school partnerships, or comparable service-learning ventures." [12]

For the purpose of this project, diversity is used to refer to any characteristic of a person is that has the potential to impact their educational experience. With that in mind, dimensions of diversity include but are not limited to race, ethnicity, sex, gender, home and primary language, religion, learning ability, and sexual orientation.

\section{Academic Context}

This graduate course was designed to analyze and develop public school curriculum. It was offered to students seeking a Master in Education Curriculum and Instruction Degree as well as students wanting to obtain initial certification for teaching (post-baccalaureate certification). It was only offered online in an asynchronous environment. This course focused on the public school curriculum and the significant factors that help determine how curriculum is constructed. Candidates use the Texas Essential Knowledge and Skills (TEKS), National Board Teacher Certification Standards (NBTS), National Association of Accredited Teacher Education Standards (NCATE) and the curriculum framework of SHSU College of Education to develop objectives and plan effective instruction. For clarity and consistency, the term student will refer to the master's students who are also EC-12 teachers or teacher candidates. The terms child and children will refer to the tutee with whom our students worked and other EC-12 children. Also, whenever names are used, they have been replaced with pseudonyms.

The students not only learned knowledge and skills related to education, but also actively used them to make a difference in the community to improve the quality of life for community members. The intent of this experience was to help the students see themselves as positive forces in the world and to deepen their understanding of their role as citizens. A minimum of nine hours was spent in field experiences in a EC-12 Texas public school classroom. Each student was responsible for arranging his or her own field experience and was required to tutor at least one child in his or her content area/certification level throughout the term of the course.

In this course, the students ranged in teaching experience from 0 to 15 years teaching experience in EC-12 Texas public schools; content certification areas contain EC-6 Generalist, Math, Grades 4-8 Math/Science, English Language Arts, English Language Learners, and Special Education. Most of 
the students were women, and approximately $50 \%$ were white and 50\% were African American. Most of the students were first generation college graduates. Their personal life experiences varied; one student, a high school teacher, has a muscular disease which confines him to a wheelchair. Other important factors include one student coming from a low socio-economic background and another student currently teaching in an overseas school.

The students were provided instructions for completing this two-part assignment. Part one was a journal in which students document dates and times of tutorial sessions, what content was taught, what teaching strategies were used, what assessments were administered and the results of the assessments, and reflections on the child's progress throughout the ACE project.

Part two of the assignment was a reflection essay focusing on their experiences and any growth or change they saw in themselves due to the tutoring sessions. While students were encouraged to discuss any topics, the following list of prompting words and phrases was provided: thoughts, ideas, successes, failures, setbacks, and how the assignment helped them become a more effective teacher. The students were also asked to document their honest, pre-conceived ideas of working with diverse learners before beginning the ACE project and to reflect on their thoughts about diverse learners after the project was complete.

The criterion of the assignment was for the student to identify and select one child to tutor in the student's academic content area with the main goal of improving the child's growth on specific learning objective(s). The child should represent the age group the student is currently teaching or plans to teach. Additionally, the child must represent a population of children whose diversity characteristics are different from the student's own diversity characteristics. For example, if the student was identified as Students with Exceptionalities then the student should select a child who has not been identified as Students with Exceptionalities. The students were told to consider diversity on the following dimensions but were encouraged to suggest other dimensions if appropriate: children with exceptionalities (e.g., children with IEPs, children identified as gifted); ethnic and/or religious diversity (may include differences in cultural characteristics, such as language, religion, and geographic/national origin); racial diversity (e.g., African American, Asian, Eastern European, Hispanic, Latino/a, Native America, Middle Eastern, South American, Western European); gender differences (including gender identity); socioeconomic diversity (e.g., middle class, lower middle class, homeless, children living in poverty, upper middle class, upper class); linguistic diversity (e.g., English language learners, student who are bilingual, students with limited English proficiency).

The primary objective of this field experience was to expose the student to a child with diversity characteristics different than their own for the purpose of increasing their experience with, helping them grow in their understanding of, and increasing their ability to effectively educate children from all backgrounds. To help guide their reflective writing, students were encouraged to consider the following topics:

- What learning strengths or weaknesses did you observe and reflect upon related to diversity characteristics of this student that affected student learning?

- What curriculum, teaching, or assessment strategies did you develop or adapt to improve student learning related to the diversity characteristics of this student? Why did you make these strategic decisions? Did these decisions improve student learning? Why?

- How did this experience and focusing on your student as a learner, help you grow as a teacher and person?

\section{Study Design}

Starting with a class-set of graduate-student reflections that had been de-identified, we determined the best way to analyze the data we had gathered was through qualitative methods. After reading several of the reflections, we decided on a document discourse analysis, focusing on how the students used language to construct and convey the meanings they attached to their lived experiences [13]. We felt this method would most appropriately lend itself to finding not only the common themes discussed across the set of papers, but would also allow us to look outlier themes that were unique to only one student as well as for unintended messages the students may not have realized they were embedding in their writing.

To further ensure we were deeply reading and understanding the students' words, rather than employing qualitative analysis software, thematic coding was completed manually. This allowed us to complete initial thematic coding of student papers to identify commonalities that presented. We were also able to explore subtleties in language usage by examining self-contradictory and inconsistent language uses, which would indicate that further scrutiny was warranted.

Finally, to ensure validity, we preserved contextualization of students' language by referring to students' verbatim language within the context of the larger reflection. This prevented 'out of context' 
interpretation of what the students' intended to say. In this case, member checking was not deemed appropriate, as students' might feel compelled to offer socially desirable justifications or contradictions to prevent appearing prejudiced against the minorities with whom they had worked [14].

\section{Findings}

While reading the students' reflections, it quickly became apparent that there were three categories into which the majority of their comments fit: language regarding the child with whom the student worked; language describing their experiences with the child; and language discussing their perception of their own professional growth. After several careful readings, we also identified a fourth category in their writing: language implying unintended outcomes. Each of these categories is discussed in more detail below.

\subsection{Descriptions of Children}

The first category of language we analyzed was discussion of the child with whom each graduate student worked. The assignment required students to describe the differences between themselves and their tutees. When reflecting on the pre-dispositions they held regarding the child they intended to tutor, the students used negative judgmental language, including words such as "rough", "frustrating", "lazy" and "challenging". One student was particularly concerned about working closely with a child so different from herself, stating, "I have to admit that I felt hesitant in the beginning. I had to overcome my fear." Another entered the project with serious apprehension, reporting, "When I first met JT, I thought he was going to be trouble, I did not think he would want to learn, and I did not think he would participate in the tutoring sessions." In describing her predispositions regarding working with a student with a social-emotional disorder, a student wrote, "I knew she would be a challenge as a student. I too, just like the other students, thought of her as "rough", inevitably low in reading and had a very unusual way of coping with uncomfortable situations i.e the snorting. I as the teacher was making judgments involuntarily before even knowing who or what made up this student."

Other students reported difficulties at the beginning of their tutorial sessions, saying they were having trouble 'reaching' their students both personally and professionally. One student wrote, "As our [first] meeting continued and MJ had my full attention in a quiet cluttered house free of distractions, she began attention seeking and avoidance behaviors. Talking like a baby, crawling under the table, having to go to the bathroom every
5 minutes, and needing a drink are just a few of the behaviors she displayed." Another reported, "After numerous attempts, very seldom was he successful in this task. Also, while he attempted to complete the reading passages, I noticed that he began displaying signs of frustration. At first I thought he was upset at having to complete the tasks. Upon further observations and contacts, I determined the frustration was localized to himself and at this failure to progress successfully through readings." One student even admitted, "My experience with African American students has basically been reduced to behavior issues. Male teachers at my school get to deal with the most problematic African American students. I didn't know what to expect of him. I was nervous at first."

When describing their beliefs and attitudes about those same children at the conclusion of the ACE project, however, the students' language changed to be considerably more positive. Students used works such as "focused", "driven", "independent", and "persistent". One student wrote, "I discovered that African American students are very energetic, enthusiastic, and really nice students." Similarly, another student wrote, "What I found out is that he is a sweet boy, full of hope and dreams. He dreams of becoming a football star or an artist. A boy that was eager to learn and be successful."

Careful analysis of the language used by the students when reflecting on their experience working with students who differ from them makes it evident that some education students, in this case practicing teachers taking classes toward earning a master's degree in education, hold negative opinions of some of the children they teach. However, through experiences such as the one offered through this ACE assignment, their opinions can be influenced, helping them to identify strengths in children where they previously saw only weaknesses and difficulties.

\subsection{Experience Descriptions}

The second category of language that we analyzed was how the students talked about the experience of tutoring a child from whom they are in some way different. While nearly all of the students reported having a positive experience, potentially as a socially desirable response to a required class assignment [14], some of the students' language was powerful, using words such as "transformative" and "life-changing". These comments, and others like them, encouraged us to look for other ways students described the impact the experience has on them. One student wrote, "AJ has helped me improve as a teacher." Another stated, "I have learned more from her that she has from me." 
What many of the students had in common in their language on describing the experience was a discussion of how they felt when the child with whom they were working started to learn and truly understand the content. Both the master's students and their tutees expressed excitement and joy in the successful learning experience, and one student reflected that the experience "brought me back to the original reason I chose teaching as my career, a love of all children." These positive reports of the experience itself were not unexpected. We believed that our students would enjoy having the opportunity to work one-on-one with a child to help the child improve academically.

\subsection{Professional Growth}

As faculty in a teacher preparation program, to us the most surprising language concerned the professional growth the students reported. We had anticipated students expressing changes in their opinions of children; we also expected students to report positive experiences during the ACE project. Since all of our students are EC-12 teachers working on a master's degree in education, we expected some measure of professional growth, but not the overwhelming amount that was reported. The professional growth students expressed was in areas that we felt they should have realized while undergraduates or in their practice in their own classrooms.

One of the most common themes in the reflections centered on differentiating lessons based on learning style, cultural background, and language acquisition. Differentiation of teaching is one of the primary threads woven throughout our undergraduate teacher preparation courses. As a leading expert in differentiated instruction, Tomlinson (2008) states differentiated "is concerned with developing not only with content master but also student efficacy and ownership of learning" [15]. In another article, Santangelo and Tomlinson claim "the overarching premise of differentiated instruction is that learning experiences need to be designed and adapted to meet students' individual and diverse needs in order to facilitate student success" [16].

We were surprised to read several students who are classroom teachers express a need to incorporate differentiated experiences into their daily lessons. One student reported, "I have also learned that all of the students will not have the same success rate and that it takes time and redesigning instruction to make sure that every student is able to be successful." This student, who included a detailed account of using her tutee's learning style to address her at an individual level, went on to comment, "This made me question whether or not I should be doing this with all of my students of all backgrounds, and I soon added this element to my teaching strategies to all my students."

Another common thread that emerged from the students' writing was the idea of integrating experiential and active learning experiences into their classroom. "It was actually cool that his learning style was kinesthetic because I got to come up with some really cool ways for him to learn," reported one student. Others noted, "I focused on reinforcing the themes that his teacher taught him during the school year [using] predominantly hands on activities," and "I was hopeful that by changing the activity every ten minutes, it would keep MJ engaged and learning. I also added a novelty pointer to reading time and an Aqua Doodle to Spelling and Word Work time to make it more 'fun'. Adding these tools helped MJ overcome some of her avoidance behaviors." Our under-graduate and postbaccalaureate certification programs emphasize the need for experiential teaching methods to help motivate children to learn in deep and meaningful ways. Although not all of our graduate students obtained initial certification at our university, the number of comments regarding the use of "childcentered" teaching methods was surprising. This experience, in the words of one student, "really made me take a long look at how and what I am teaching."

\subsection{Unintended Outcomes}

Although service-learning programs such as ACE are gaining popularity not only in the United States but also around the globe, they are not without critics. One concern of critics discuss is unintended consequences, that a service learning course component may actually do more harm than good in addressing stereotypes and biases. One argument is that short-term interaction, such as the nine-hour minimum for this project, may actually solidify some students' negative attitudes and opinions of others [17]. While none of our students reported confirmed or strengthened stereotypes or biases, we did identify language that concerned us.

In reading student reflections, there were a couple of instances of elitism: the egocentric belief that what is valued in one person's culture should be valued in other cultures. The clearest example was written by a student who had worked with a Hispanic child living in poverty in a single-parent household. The student wrote, "I realized that he does not have really high expectations so far for himself, about his future, he wants to become a Taxi Driver; not a teacher or a lawyer or a doctor. I see that this expectation might come from his economic background." To the student, the child's professional goals are not "high" enough. Teaching or practicing law or medicine are worthy goals; being a taxi driver is not. 
Another student wrote, "I also learned that uninvolved parents are at every socio-economic level. Belle is from a middle-class family and a very detached family. Mom is the primary caregiver because Dad travels, but Mom is tired and unmotivated to deal with Belle and her antics. Belle's Mom has yet to work with Belle on the days that I am not meeting with her. I understand that most parents work all day and they are very tired, but when you have a child, the child becomes or should become a priority." This student is critical of the parenting the child receives, and does not equate working hard to provide material goods for children to being an "engaged" parent. Because the student values one-on-one time between parents and children, she believes others should value this time as well.

Elitism was not the only unintended outcome we identified. When discussing a child with both learning disabilities and health concerns, one student stated, "A child like Anna reminds me daily of how blessed I am to have two healthy children of my own, and how quickly that all could change and does change for some parents." While not intending to place Anna in the category of 'lessor than,' this student clearly does not appreciate the value that Anna brings to the educational context in which she is taught. This student reports having "compassion" for the parents, again, using language that reveals an underlying belief that working with Anna is "frustrating for the teacher". Although this student "learned more from [the child] than she has from me," her conclusions uncover an unexpected and undesirable opinion of children like Anna.

Finally, we encountered one student who overgeneralized the positive experience with diverse learners. To conclude the reflection, this student wrote, "I discovered that African American students are very energetic, enthusiastic, and really nice students." There is just as much harm in positive biases as there are in negative biases. Failure to treat children as individuals can lead to not realizing learning styles, emotional needs, or other characteristics that make us all unique.

\section{Discussion and Conclusion}

As inclusion of service-learning components in university and college courses gains in popularity, researchers must look at the results of those projects and the benefits that are realized. With over 36,000 hours of work completed each semester by students in ACEd courses at our university alone, there is an enormous amount of effort and energy being dedicated to service-learning opportunities, not to mention the expenditure of university resources to organize and run such programs. The project these authors examined from a graduate-level teacher education course yielded a variety of lived experiences, and careful examination uncovered a variety of outcomes including some that were not intended.

Research on social learning shows that combining volunteerism with course objectives is a powerful way to not only promote deep and meaningful learning in students but can also be used to give back to the communities in which colleges and universities operate [18]. The reciprocal nature of service learning is echoed by Ball, who insists that the reciprocity of the service is what distinguished service learning experiences. Without benefit to both servant and served there is only either service or learning, not both [19].

We conclude that engaging graduate students in service-learning experiences provides opportunities for them to interact meaningfully with children from various backgrounds. It has allowed us to better prepare our students for becoming culturally responsive educators. Feedback from university students shows that they benefited from the project at least as much as did the children with whom they worked. Qualitative analysis shows significant growth in understanding of others' needs and dramatic differences in empathy for students who seem disengaged and unmotivated. Additionally, education students report a newfound motivation to identify contextual factors contributing to their students' academic dispositions. The authors believe these data support the positive impacts this project had on our students' dispositions toward working with diverse learners.

However, the authors believe some of the growth, for some of the students, is only superficial or in some other way had an unintended outcome. The requirement of nine contact hours is minimal and may have led some students to superficially address their own biases, provide socially acceptable responses, or state an over correction of their preconceived ideas about students with differences. Despite some of the unintended outcomes, we believe in the ACE program and intent to continue having our students work with diverse learners. To improve the outcomes, we posit that expanding the required number of hours would most likely provide a more meaningful learning experience for both the student and the child.

Like many teacher preparation programsundergraduate and graduate-our university provides the students with service-learning experiences to increase their knowledge of the individual learning needs of students. While further research is warranted to determine what long-term effects these field experiences have on our students' classroom practices, we would like to leave you with the following quote:

This experience transformed me as a teacher of diverse learners in a very significant manner. First, I had to 
identify culturally and linguistically with Manuel and understand his background before we could begin discussing anything academic. Next, I had to truly dissect his strengths and weaknesses using a variety of strategies. Once I recognized the different ways in which Manuel learned best, I tapped into it and found resources to meet his needs. By taking the time to focus on Manuel and his needs, I was able to transfer the learning methods and accommodations to help enhance all of my students over time. By understanding the needs of the diverse learners and how to meet those needs in new and innovative ways, the opportunities for learning and understanding can grow exponentially.

\section{References}

[1] Adams, J., Lee, S., \& Cortese, J. (2012). The acceptability of online degrees: Principals and hiring practices in secondary schools. Contemporary Issues in Technology and Teacher Education, 12(4), 408-422.

[2] Brown, L. O. (2012). South Dakota secondary school students' science attitudes and the implementation of NASA's Digital Learning Network's 'Can A Shoebox Fly? Challenge'. Dissertation Abstracts International Section A, 72,3205 .]

[3] Allen, I. E., \& Seaman, J. (2013). Changing courses: Ten years of tracking online education. Babson Park, MA: Babson Survey Research Group and Quahog Research Group, LLC. Retrieved from http://files.eric.ed.gov/fulltext/ED541571.pdf

[4] Bringle, R. G., Hatcher, J. A., \& Muthiah, R. N. (2010). The role of service-learning on the retention of first-year students to second year. Michigan Journal of Community Service Learning, 16(2), 38-49. Retrieved from

http://quod.lib.umich.edu/m/mjcsl/3239521.0016.203/1

[5] National Survey of Student Engagement (2002). The NSSE 2002 report: National benchmarks of effective educational practice. Bloomington, IN: Indiana University Center for Postsecondary Research and Planning.

[6] Kuh, G. D. (2008). High-Impact Educational Practices: What They Are, Who Has Access To Them, And Why They Matter. Washington, DC: Association of American Colleges and Universities.

[7] Colby, S. L., \& Ortman, J. M. (2015). Projections of Size and Composition of the U. S. Population: 2014 to 2060. United States Census Bureau. Retrieved from https://www.census.gov/content/dam/Census/library/publi cations/2015/demo/p25-1143.pdf
[8] Banks, J.A. (2008). Diversity, group identity, and citizenship in a global age. Educational Researcher, 37(3), 129-139.

[9] Eyler, J., Giles, Jr. D. E., Stenson, C. M., \& Gray, C. J. (2001). At a glance: What we know about the effects of service-learning on college students, faculty, institutions, and communities, 1993-2000. Retrieved from http://digitalcommons.unomaha.edu/cgi/viewcontent.cgi?a rticle $=1001 \&$ context $=$ slcebibliography

[10] Edwards, C. J., Carr, S., \& Siegel, W. (2006). Influences of experiences and training on effective teaching practices to meet the needs of diverse learners in schools. Education, 126(3), 580-592.

[11] Kim, Y., \& Yazdian, L. S. (2014). Portfolio Assessment and Quality Teaching. Theory Into Practice, 53(3), 220-227. doi:10.1080/00405841.2014.916965

[12] Fitchett, P. G., Starker, T. V., \& Salyers, B. (2012). Examining Culturally Responsive Teaching Self-Efficacy in a Preservice Social Studies Education Course. Urban Education, 47(3), 585-611. doi: $10.1177 / 0042085912436568$

[13] Jupp, V. (2006). The Sage Dictionary of Social Research Methods. Thousand Oaks, CA: Sage.

[14] Lewis-Beck, M. S., Bryman, A., \& Liao, T. F. (2003). The Sage Encyclopedia of Social Science Research Methods. Thousand Oaks, CA: Sage.

[15] Tomlinson, C. A. (2008). The Goals of Differentiation. Educational Leadership, 66(3), 26-30.

[16] Santangelo, T., \& Tomlinson, C. A. (2008). The Application of Differentiated Instruction in Postsecondary Environments: Benefits, Challenges, and Future Directions. International Journal Of Teaching \& Learning In Higher Education, 20(3), 307-323.

[17] Kirkland, D. E. (2014). "They look scared": Moving from service learning to learning to serve in teacher education-A social justice perspective. Equity \& Excellence in Education, 47(4), 580-603. DOI:10.1080/10665684.2014.958967

[18] Groh, C. J., Stallwood, L. G., \& Daniels, J. J. (2011). Service learning in nursing education: Its impact on leadership and social justice. Nursing Education Perspectives, 32(6), 400-405.

[19] Ball, M. A. (2008). Practicums and service learning in LIS education. Journal of Education for Library and Information Science, 49(1), 70-82. 